\title{
Cigarette smoke-induced neurogenic inflammation is mediated by $\alpha, \beta$-unsaturated aldehydes and the TRPA1 receptor in rodents
}

\author{
Eunice Andrè, ${ }^{1}$ Barbara Campi, ${ }^{1}$ Serena Materazzi, ${ }^{2}$ Marcello Trevisani, ${ }^{1}$ Silvia Amadesi, ${ }^{3}$ \\ Daniela Massi, ${ }^{4}$ Christophe Creminon, ${ }^{5}$ Natalya Vaksman, ${ }^{3}$ Romina Nassini, ${ }^{2}$ Maurizio Civelli, ${ }^{6}$ \\ Pier Giovanni Baraldi, ${ }^{7}$ Daniel P. Poole, ${ }^{3}$ Nigel W. Bunnett, ${ }^{3}$ \\ Pierangelo Geppetti, ${ }^{1,2}$ and Riccardo Patacchini ${ }^{6}$
}

\begin{abstract}
${ }^{1}$ Center of Excellence for the Study of Inflammation, University of Ferrara, Ferrara, Italy. ${ }^{2}$ Clinical Pharmacology Unit, Department of Critical Care Medicine and Surgery, University of Florence, Florence, Italy. ${ }^{3}$ Departments of Physiology and Surgery, UCSF, San Francisco, California, USA. ${ }^{4}$ Department of Human Pathology and Oncology, University of Florence, Florence, Italy. ${ }^{5} \mathrm{CEA}$, Institut de Biologie et Technologies de Saclay (iBiTec-S), Service de pharmacologie et d'immuno analyse (SPI), Gif sur Yvette, France. ${ }^{6}$ Pharmacology Department, Chiesi Pharmaceuticals, Parma, Italy. ${ }^{7 D e p a r t m e n t ~ o f ~ P h a r m a c e u t i c a l ~ C h e m i s t r y, ~ U n i v e r s i t y ~ o f ~ F e r r a r a, ~ F e r r a r a, ~ I t a l y . ~}$
\end{abstract}

\begin{abstract}
Cigarette smoke (CS) inhalation causes an early inflammatory response in rodent airways by stimulating capsaicin-sensitive sensory neurons that express transient receptor potential cation channel, subfamily $V$, member 1 (TRPV1) through an unknown mechanism that does not involve TRPV1. We hypothesized that $2 \alpha, \beta$-unsaturated aldehydes present in CS, crotonaldehyde and acrolein, induce neurogenic inflammation by stimulating TRPA1, an excitatory ion channel coexpressed with TRPV1 on capsaicin-sensitive nociceptors. We found that CS aqueous extract (CSE), crotonaldehyde, and acrolein mobilized $\mathrm{Ca}^{2+}$ in cultured guinea pig jugular ganglia neurons and promoted contraction of isolated guinea pig bronchi. These responses were abolished by a TRPA1-selective antagonist and by the aldehyde scavenger glutathione but not by the TRPV1 antagonist capsazepine or by ROS scavengers. Treatment with CSE or aldehydes increased $\mathrm{Ca}^{2+}$ influx in TRPA1-transfected cells, but not in control HEK293 cells, and promoted neuropeptide release from isolated guinea pig airway tissue. Furthermore, the effect of CSE and aldehydes on $\mathrm{Ca}^{2+}$ influx in dorsal root ganglion neurons was abolished in TRPA1-deficient mice. These data identify $\alpha, \beta$-unsaturated aldehydes as the main causative agents in CS that via TRPA1 stimulation mediate airway neurogenic inflammation and suggest a role for TRPA1 in the pathogenesis of CS-induced diseases.
\end{abstract}

\section{Introduction}

Inhaled cigarette smoke (CS) causes an early inflammatory response in the airways that is partly neurogenic (1). In rodents, CS-evoked neurogenic plasma protein leakage (1) is mediated by release of the neuropeptides substance P (SP) and neurokinin A (NKA) from capsaicin-sensitive sensory nerves that activate tachykinin NK1 receptors in postcapillary venules to cause edema (2). The neurogenic mechanism of CS-evoked plasma extravasation in the airways was discovered because it was absent in capsaicinpretreated rats, in which SP-containing C-fiber nociceptors in the respiratory tract had degenerated (1). Although desensitization of sensory nerves by capsaicin is due to its unique ability to stimulate the transient receptor potential cation channel, subfamily $V$, member 1 (TRPV1) $(3,4)$, TRPV1 does not mediate the neuronal action of CS, because the selective TRPV1 receptor antagonist capsazepine (5) failed to prevent CS-evoked plasma protein extravasation (6). Hence, the molecular entity expressed by sensory neurons, which mediates CS-evoked neurogenic inflammation, is unknown.

Nonstandard abbreviations used: $\left[\mathrm{Ca}^{2+}\right]$, intracellular $\mathrm{Ca}^{2+} ; \mathrm{CGRP}$, calcitonin gene-related peptide; CS, cigarette smoke; CSE, CS aqueous extract; DRG, dorsal root ganglia; GSH, glutathione monoethylester; JG, jugular ganglia; -LI, -like immunoreactivity; NKA, neurokinin $\mathrm{A}$; RR, ruthenium red; SP, substance P; TRP, transient receptor potential; TRPA1, TRP cation channel, subfamily A, member 1; TRPV1, TRP cation channel, subfamily $\mathrm{V}$, member 1 .

Conflict of interest: The authors have declared that no conflict of interest exists. Citation for this article: J. Clin. Invest. 118:2574-2582 (2008). doi:10.1172/JCI34886.
In addition, the chemical components among the approximately 5,000 constituents of CS that cause airway neurogenic inflammation are unknown. Thus, some 25 years after the original observation made by Lundberg and Saria (1), both the chemical components of CS and their molecular target on sensory neurons remain to be identified. Ruthenium red (RR), an inorganic dye initially reported to prevent capsaicin-evoked responses (7) and now recognized as a nonspecific blocker of TRP channels, reportedly reduces CS-induced tracheal plasma extravasation (6). From this apparently contradictory observation, made at a time (1993) when none of the presently recognized TRP channels had been described, we now hypothesize that one or more additional TRPs expressed by sensory neurons could be the molecular target(s) of CS in producing airway neurogenic inflammation.

In addition to TRPV1 (3), other TRP channels are expressed by C-fiber nociceptors. These include TRPV2, TRPV3, and TRPV4 (gated by warm, non-noxious, and noxious temperatures and small reductions in tonicity) and TRPM8 (activated by menthol and moderate low temperature) (8-13). ANKTM1, renamed TRPA1 (TRP cation channel, subfamily A, member 1 ), is a recently identified channel that is almost entirely coexpressed with TRPV1 on sensory neurons, including vagal neurons innervating the airways (14-16). TRPA 1 is activated by isothiocyanates, thiosulfinate, or cinnamaldehyde compounds, which are the pungent ingredients found in mustard, garlic, and cinnamon, respectively (17-20). A recent study showed that the irritant $\alpha, \beta$-unsaturated aldehyde, acrolein, is a 

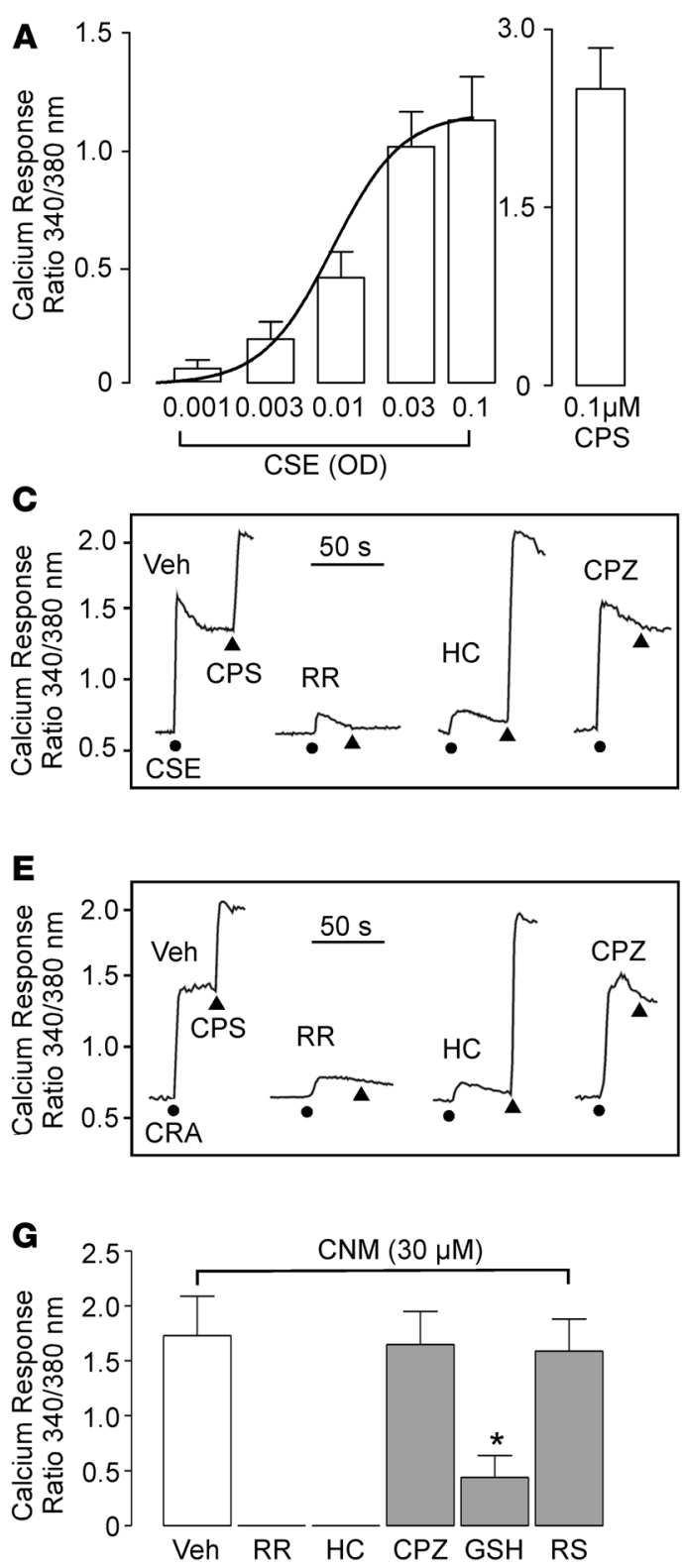
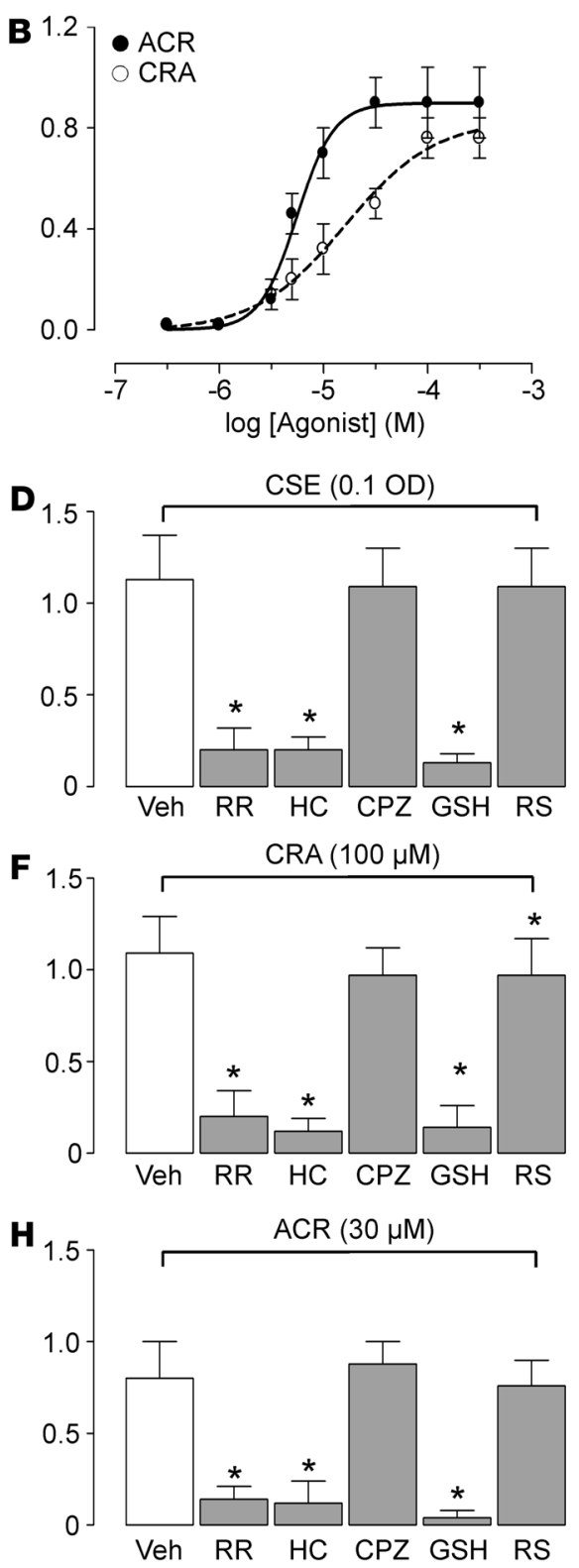

\section{Figure 1}

CSE and unsaturated aldehydes increase intracellular $\mathrm{Ca}^{2+}$ in guinea pig JG neurons. [ $\left.\mathrm{Ca}^{2+}\right]_{i}$ mobilization in cultured guinea pig JG neurons by CSE and capsaicin (CPS) (A) or acrolein (ACR) and crotonaldehyde (CRA) (B). Typical traces (C and E) and pooled data (D and $\mathbf{F}-\mathbf{H})$, showing the effect of RR $(1 \mu \mathrm{M})$, HC-030031 (HC; $30 \mu \mathrm{M})$, GSH (10 $\mathrm{mM})$, capsazepine (CPZ; $10 \mu \mathrm{M})$, or a combination of ROS scavengers (RS; mannitol, 20 mM; ascorbic acid, $100 \mu \mathrm{M}$; lycopene, $10 \mu \mathrm{M}$; and $\beta$-carotene, $10 \mu \mathrm{M})$ on $\left[\mathrm{Ca}^{2+}\right]_{\mathrm{i}}$ mobilization in cultured JG neurons from the guinea pig, induced by CSE $(0.1 \mathrm{OD})$, crotonaldehyde (100 $\mu \mathrm{M}$; circles), capsaicin $(0.1$ $\mu \mathrm{M}$; triangles), acrolein (30 $\mu \mathrm{M})$, and cinnamaldehyde (CNM; 30 $\mu \mathrm{M})$. Each column represents the mean \pm SEM value of at least 21 cells. ${ }^{*} P<0.05$ versus vehicle (Veh) (1-way ANOVA, followed by Bonferroni's test).
TRPA1 stimulant (18). Since acrolein and another $\alpha, \beta$-unsaturated aldehyde, crotonaldehyde, are abundantly contained in CS $(21,22)$, we hypothesized that stimulation of TRPA1 on capsaicin-sensitive sensory neurons by $\alpha, \beta$-unsaturated aldehydes is the underlying mechanism of CS-evoked neurogenic inflammation in the airways. Herein we present direct pharmacological and genetic evidence that supports our hypothesis. This evidence clarifies the molecular mechanisms underlying the neurogenic inflammatory response activated by the exposure to CS and might be relevant for understanding the pathogenesis of smoke-induced diseases, including chronic obstructive pulmonary disease (COPD).

\section{Results}

$\mathrm{Ca}^{2+}$ mobilization in guinea pigjugular ganglia neurons. Exposure to CS aqueous extract (CSE) (0.001-0.1 OD) caused a rapidly developing and concentration-dependent mobilization of intracellular $\mathrm{Ca}^{2+}\left(\left[\mathrm{Ca}^{2+}\right]_{i}\right)$ in cultured guinea pig jugular ganglia (JG) neurons
(Figure 1, A and C). CSE vehicle had no effect (data not shown). All cells that responded to CSE invariably responded to capsaicin $(1 \mu \mathrm{M})$. Crotonaldehyde and acrolein have been previously found to be the most abundant $\alpha, \beta$-unsaturated aldehydes present in CSE prepared according to the previously described method (21, 22) Therefore, we decided to challenge guinea pig JG neurons with these aldehydes to determine whether they mimic the CSE-evoked effect. In cultured neurons, acrolein and crotonaldehyde caused a concentration-dependent, prompt, and sustained mobilization of $\left[\mathrm{Ca}^{2+}\right]_{\mathrm{i}} . \mathrm{EC}_{50}$ were $5 \mu \mathrm{M}(\mathrm{CI}, 4-8)$ and $16 \mu \mathrm{M}(\mathrm{CI}, 7-36)$, respectively (Figure 1B). $\mathrm{Ca}^{2+}$ responses to CSE, acrolein, or crotonaldehyde in guinea pig JG neurons were inhibited by the nonselective TRPA1 antagonists, RR ( $1 \mu \mathrm{M}$; > $80 \%$ reduction; Figure $1, \mathrm{C}-\mathrm{F}$ and $\mathrm{H})$ or camphor (23) ( $1 \mathrm{mM}$; >80\% reduction; data not shown), whereas the selective TRPV1 antagonist, capsazepine $(10 \mu \mathrm{M})$, was ineffective (Figure 1, C-F and $\mathrm{H}$ ). More importantly, the selective TRPA1 receptor antagonist, HC-030031 (30 $\mu \mathrm{M})(24)$, abated by 
A
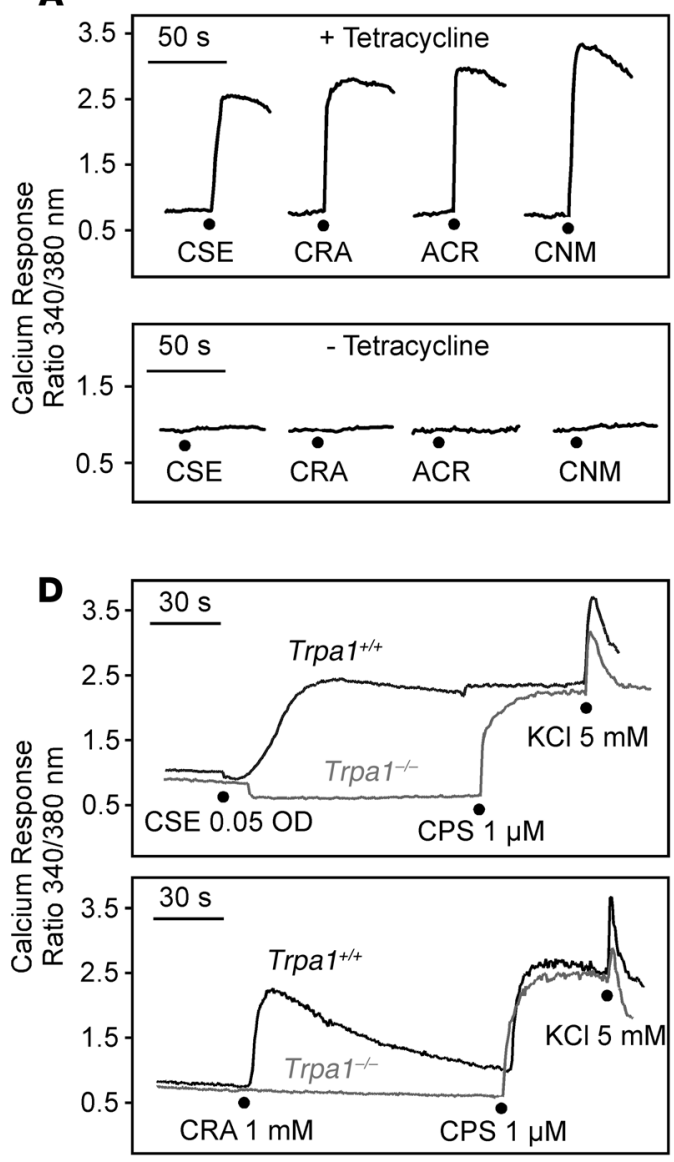

B
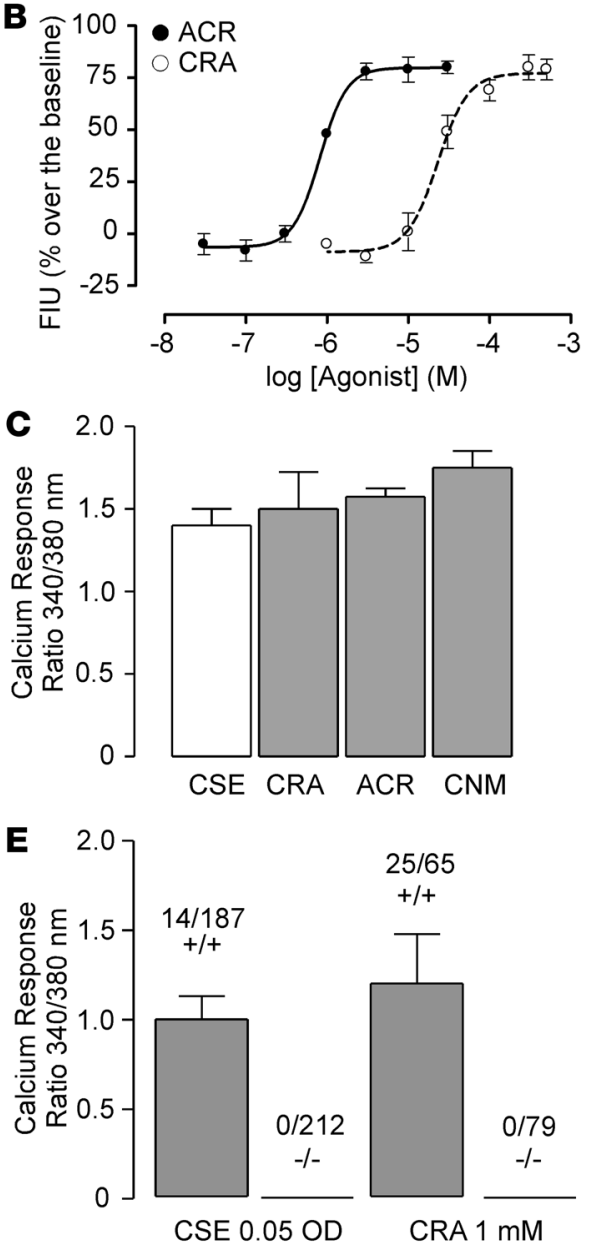

\section{Figure 2}

CSE and unsaturated aldehydes increase intracellular $\mathrm{Ca}^{2+}$ in TRPA1transfected cells. (A) Typical traces and $(\mathbf{C})$ pooled data of $\left[\mathrm{Ca}^{2+}\right]_{i}$ mobilization in HEK293 cells transfected with the CDNA of the rat TRPA1 (rTRPA1-HEK cells) in absence or presence of tetracycline and exposed to CSE (0.1 OD), crotonaldehyde $(50 \mu \mathrm{M})$, acrolein $(30 \mu \mathrm{M})$ or cinnamaldehyde $(50 \mu \mathrm{M})$. (B) Concentration-response curves to acrolein or crotonaldehyde in ITRPA1-HEK cells. Pooled data are expressed as mean \pm SEM of at least 25 cells. FIU, fluorescence intensity unit. Typical traces (D) and pooled data (E) of $\left[\mathrm{Ca}^{2+}\right]_{\mathrm{i}}$ mobilization in DRG neurons from Trpa1+/+ or Trpa1-/- mice exposed to CSE, crotonaldehyde, capsaicin, or KCl. Numbers in $\mathbf{E}$ indicate the number of responding cells/ total cells examined. more than $80 \%$ the responses evoked by CSE, acrolein, or crotonaldehyde (Figure 1, C-F and $\mathrm{H}$ ). The unsaturated aldehyde and ROS scavenger, glutathione monoethylester (GSH, $10 \mathrm{mM}$ ), also reduced these evoked responses by about $90 \%$ (Figure 1, D, F, and $\mathrm{H})$, whereas a combination of scavengers, reportedly effective in scavenging a variety of ROS, including mannitol (20 mM), ascorbic acid $(100 \mu \mathrm{M})$, lycopene $(10 \mu \mathrm{M})$, and $\beta$-carotene $(10 \mu \mathrm{M})$, did not affect the $\mathrm{Ca}^{2+}$ responses to CSE, acrolein, or crotonaldehyde (Figure 1, C-F and $\mathrm{H}$ ).

A recent paper (25) showed that $\mathrm{H}_{2} \mathrm{O}_{2}$ produces a delayed $\mathrm{Ca}^{2+}$ response in mouse dorsal root ganglia (DRG) neurons. This response was ascribed to the TRPA1 channel stimulation, because it was absent in neurons from TRPA1-deficient mice. In guinea pig JG neurons, we found that $\mathrm{H}_{2} \mathrm{O}_{2}$ causes a concentration-related (0.1-5 mM) response. $\mathrm{EC}_{50}$ was $0.65 \mathrm{mM}$ (CI, 0.32-1.8). The response to $\mathrm{H}_{2} \mathrm{O}_{2}$, as shown previously (25), was delayed in onset (responses initiated 20-40 seconds and reached a plateau 60-200 seconds after the addition of the stimulus). The $\mathrm{Ca}^{2+}$ response to $1 \mathrm{mM} \mathrm{H}_{2} \mathrm{O}_{2}$ (change in $\mathrm{F}_{340} / \mathrm{F}_{380}, 0.503 \pm 0.08 ; n=28$ ) was markedly reduced by the combination of the 4 ROS scavengers: mannitol (20 $\mathrm{mM})$, ascorbic acid $(100 \mu \mathrm{M})$, lycopene $(10 \mu \mathrm{M})$, and $\beta$-carotene $(10 \mu \mathrm{M})$ (change in $\left.\mathrm{F}_{340} / \mathrm{F}_{380}, 0.176 \pm 0.02 ; n=32 ; P<0.01\right)$.

The selective agonist of the TRPA 1 channel, cinnamaldehyde (17), evoked a robust $\mathrm{Ca}^{2+}$ response that was abolished by RR, HC030031, and GSH and was not affected by capsazepine or by ROS scavengers (Figure 1G). Acetaldehyde, the most abundant saturated aldehyde present in $\operatorname{CSE}(21,26,27)$, has recently been reported to stimulate, at $\mathrm{mM}$ concentrations, recombinant and wild-type (mouse DRG neurons) TRPA1 $(28,29)$. Acetaldehyde in concentrations up to $1 \mathrm{mM}$ did not cause any $\mathrm{Ca}^{2+}$ response in guinea pig JG neurons but caused a moderate response at 5 - $\mathrm{mM}$ concentration (change in $\left.\mathrm{F}_{340} / \mathrm{F}_{380}, 0.4 \pm 0.07 ; n=40\right)$. However, that moderate response was resistant to $\mathrm{HC}-030031\left(100 \mu \mathrm{M}\right.$; change in $\mathrm{F}_{340} / \mathrm{F}_{380}$, $0.36 \pm 0.08 ; n=32)$. Nicotine has been recently shown to mobilize $\left[\mathrm{Ca}^{2+}\right]_{i}$ in cultured primary sensory neurons in a hexamethonium-sensitive manner (30). In the present study, nicotine $(10 \mu \mathrm{M})$ increased $\left[\mathrm{Ca}^{2+}\right]_{\mathrm{i}}$ mobilization (change in $\mathrm{F}_{340} / \mathrm{F}_{380}, 0.89 \pm 0.12$; $n=43$ ) in JG neurons, a response that was inhibited by $100-\mu \mathrm{M}$ hexamethonium (change in $\mathrm{F}_{340} / \mathrm{F}_{380}, 0.12 \pm 0.02 ; n=37 ; P<0.05$ ) and by $2-\mu \mathrm{M}$ mecamylamine (change in $\mathrm{F}_{340} / \mathrm{F}_{380}, 0.18 \pm 0.03$; $n=19 ; P<0.05$ ) but not by $30-\mu \mathrm{M} \mathrm{HC}-030031$ (change in $\mathrm{F}_{340} / \mathrm{F}_{380}$, $0.78 \pm 0.17 ; n=18 ; \mathrm{NS})$. In contrast, CSE-evoked (0.1 OD) increase in $\left[\mathrm{Ca}^{2+}\right]_{\mathrm{i}}$ (change in $\mathrm{F}_{340} / \mathrm{F}_{380}, 1.32 \pm 0.23 ; n=28$ ) was not affected by either hexamethonium $\left(100 \mu \mathrm{M}\right.$; change in $\mathrm{F}_{340} / \mathrm{F}_{380}, 1.44 \pm 0.19$; $n=33$ ) or mecamylamine (change in $\mathrm{F}_{340} / \mathrm{F}_{380}, 1.28 \pm 0.23$; $n=16$ ). Thus, the role of ROS, saturated aldehydes, and nicotine in CSEevoked $\mathrm{Ca}^{2+}$ mobilization seems to be absent or minor.

$\mathrm{Ca}^{2+}$ mobilization in HEK293 cells and mouse DRG neurons. In HEK293 cells transfected with rat TRPA1 cDNA (rTRPA1HEK293) and treated with tetracycline to induce TRPA1, exposure 

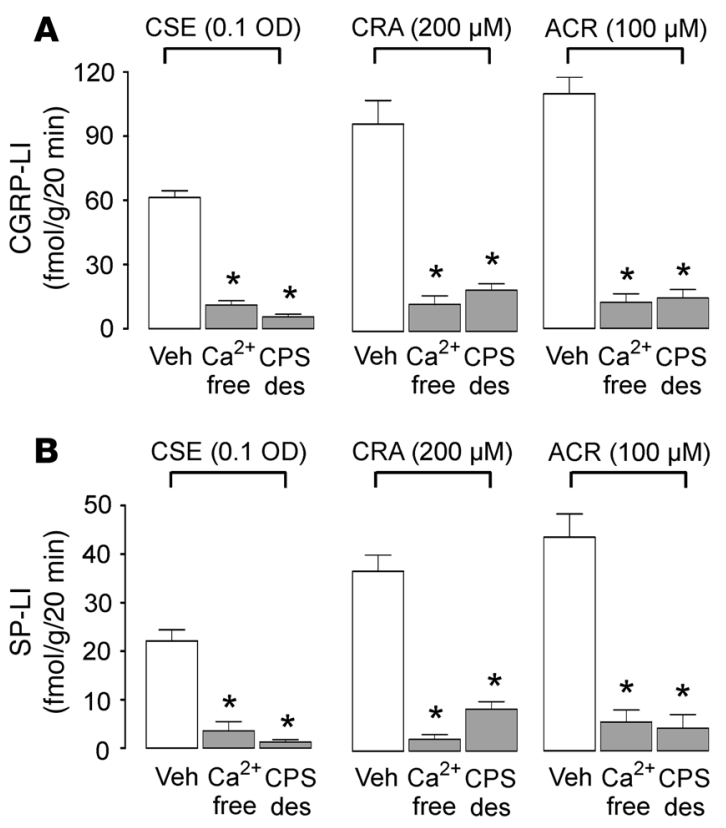

Figure 3

CSE and unsaturated aldehydes promote neuropeptide release from guinea pig airways. (A) CGRP-LI and (B) SP-LI release induced by CSE, acrolein, or crotonaldehyde from slices of guinea pig airways. Experiments were performed in a $\mathrm{Ca}^{2+}$-free medium plus $1 \mathrm{mM}$ EDTA ( $\mathrm{Ca}^{2+}$ free), after capsaicin desensitization (CPS des; $10 \mu \mathrm{M}$ for 20 minutes), or in a normal medium with the vehicle of capsaicin. Each column represents the mean \pm SEM of at least 5 experiments. ${ }^{\star} P<0.05$ versus Veh (1-way ANOVA, followed by Bonferroni's test).

to CSE, acrolein, or crotonaldehyde caused a remarkable increase in $\left[\mathrm{Ca}^{2+}\right]_{\mathrm{i}}$ mobilization. rTRPA1-HEK293 cells also responded to cinnamaldehyde (Figure 2, A and C). $\mathrm{EC}_{50}$ for acrolein and crotonaldehyde were $0.8 \mu \mathrm{M}$ (CI, 0.7-0.9) and $23 \mu \mathrm{M}$ (CI, 16-33), respectively (Figure $1 \mathrm{~B}) . \mathrm{Ca}^{2+}$ responses to $\mathrm{CSE}(0.1 \mathrm{OD})$ (change in $\left.\mathrm{F}_{340} / \mathrm{F}_{380}, 1.42 \pm 0.21 ; n=38\right)$, acrolein $\left(1 \mu \mathrm{M}\right.$; change in $\mathrm{F}_{340} / \mathrm{F}_{380}$, $1.08 \pm 0.16 ; n=24)$, or crotonaldehyde $\left(25 \mu \mathrm{M}\right.$; change in $\mathrm{F}_{340} / \mathrm{F}_{380}$, $1.41 \pm 0.28 ; n=25)$ were not affected by a combination of ROS scavengers (mannitol, $20 \mathrm{mM}$; ascorbic acid, $100 \mu \mathrm{M}$; lycopene, $10 \mu \mathrm{M}$; and $\beta$-carotene, $10 \mu \mathrm{M})\left(\right.$ change in $\mathrm{F}_{340} / \mathrm{F}_{380}, 1.38 \pm 0.2$; $n=35 ; 0.97 \pm 0.12, n=23$; and $1.32 \pm 0.22, n=27$; respectively). rTRPA1-HEK293 cells that were not treated with tetracycline (and therefore did not express TRPA1) (Figure 2A, bottom panel) and HEK293 cells transfected with empty vector (data not shown) failed to respond to CSE, crotonaldehyde, acrolein, or cinnamaldehyde. Thus, expression of TRPA1 was the necessary condition to confer onto HEK293 cells the ability to respond to unsaturated aldehydes and CSE.

In cultured DRG neurons from $\operatorname{Trpa1}^{+/+}$mice, crotonaldehyde induced a prompt and sustained $\mathrm{Ca}^{2+}$ response in some neurons that responded to capsaicin (Figure 2, D, bottom panel, and E). In contrast, crotonaldehyde was completely inactive in neurons from Trpa1 ${ }^{-1-}$ mice (Figure 2, D, bottom panel, and E). CSE (0.05 OD) induced a rapidly developing and sustained increase in baseline fluorescence in some neurons from $\operatorname{Trpa1} 1^{+/+}$mice (Figure 2, D, top panel, and E). All neurons from Trpa1 ${ }^{+/+}$mice that responded to CSE were sensitive to capsaicin. However, CSE was completely inactive in neurons from $\mathrm{Trpa1}^{-/-}$mice, neurons that had responded normally to capsaicin (Figure 2, D, top panel, and E). Overall, these results show that both crotonaldehyde and CSE effects in mouse DRG neurons are mediated by TRPA1.

Calcitonin gene-related peptide and SP release from guinea pig airways. CSE strongly stimulated the outflow of SP-like immunoreactivity (SP-LI) and of another major sensory neuropeptide (2), the calcitonin gene-related peptide-LI (CGRP-LI), from slices of guinea pig airways (Figure 3). This effect was significantly reduced when tissues were incubated in $\mathrm{Ca}^{2+}$-free medium (93\% and $87 \%$ reduction, respectively) or in preparations desensitized to capsaicin $(20 \mu \mathrm{M}$ for 20 minutes) (77\% and $80 \%$ reduction, respectively) (Figure 3 ). Exposure to acrolein or crotonaldehyde for 10 minutes also caused a significant increase in the outflow of SP-LI and CGRP-LI. These responses were significantly reduced ( $>80 \%$ reduction) when experiments were performed in a $\mathrm{Ca}^{2+}$-free medium or after capsaicin desensitization (Figure 3). Thus, CSE and unsaturated aldehydes cause a $\mathrm{Ca}^{2+}$-dependent release of neuropeptides from capsaicinsensitive airway sensory nerve terminals.

Organ bath studies. Exposure of isolated guinea pig bronchial rings to CSE (0.02-0.1 OD) in the presence of indomethacin $(5 \mu \mathrm{M})$ and atropine $(1 \mu \mathrm{M})$ caused a concentration-dependent (data not shown), rapidly developing, and sustained contraction that at $0.1 \mathrm{OD}$ was $68 \pm 5 \%$ of that produced by carbachol $(1 \mu \mathrm{M}$; $n=12$; added before atropine) (Figure $4 \mathrm{~A}$ ). The response to CSE was inhibited by capsaicin desensitization $(20 \mu \mathrm{M}$ for 20 minutes) of sensory nerve terminals, RR $(30 \mu \mathrm{M})$, the combination of SR 140333 and SR 48968 (NK1 and NK2 tachykinin receptor antagonists, respectively; both $1 \mu \mathrm{M})$, HC-030031 (50 $\mu \mathrm{M})$, camphor (1 mM; data not shown), and GSH (10 mM) (Figure 4, A and B). In contrast, the response to CSE was unaffected by either capsazepine $(10 \mu \mathrm{M})$ or the combination of 4 ROS scavengers: mannitol (20 $\mathrm{mM})$, ascorbic acid $(100 \mu \mathrm{M})$, lycopene $(10 \mu \mathrm{M})$, and $\beta$-carotene $(10 \mu \mathrm{M})($ Figure 4B). As with CSE, contractions evoked by acrolein and crotonaldehyde were inhibited by capsaicin pretreatment, RR, the combination of NK1 and NK2 tachykinin receptor antagonists, HC-030031, camphor (1 mM; data not shown), and GSH but were unaffected by capsazepine or a combination of 4 ROS scavengers (Figure 4, C, D, and F). Cinnamaldehyde caused a capsaicin-sensitive contraction of isolated guinea pig bronchi, which was inhibited by RR, NK1 and NK2 tachykinin receptor blockade, HC-030031, camphor (1 mM, not shown), and GSH but was not affected by capsazepine, mannitol, or a combination of 4 ROS scavengers (Figure 4E). Thus, CSE and unsaturated aldehydes contract the guinea pig bronchus by a neurogenic mechanism mediated by TRPA1 stimulation.

Plasma extravasation. Evans blue dye extravasation was significantly greater in the trachea $(26.1 \pm 5.3 \mathrm{ng} / \mathrm{g}$ of tissue; $n=11)$ of anesthetized guinea pigs that inhaled CS than in those that inhaled room air $(8 \pm 1.6 \mathrm{ng} / \mathrm{g}$ of tissue; $n=9 ; P<0.05)$ (Figure $5 \mathrm{~A})$. This response was significantly reduced by pretreatment with $R R$ via intratracheal instillation $(4.5 \mathrm{nmol} / 150 \mu \mathrm{l} ; 74 \%$ reduction $)$ or $\mathrm{HC}$ 030031 (45 nmol $/ 150 \mu \mathrm{l} ; 91 \%$ reduction). In contrast, pretreatment with intratracheal instillation of capsazepine (45 nmol/150 $\mu \mathrm{l})$ failed to prevent CS-induced dye extravasation (Figure 5A). Selectivity of HC-030031 and capsazepine was tested in guinea pigs treated with capsaicin. The increase in plasma extravasation evoked by capsaicin $(1 \mu \mathrm{mol} / \mathrm{kg}$, i.v.) was abolished by capsazepine and was unaffected by HC-030031 (Figure 5B). Intratracheal instillation of RR, HC-030031, capsazepine, or their respective vehicles did not affect baseline plasma protein extravasation. Instillation 

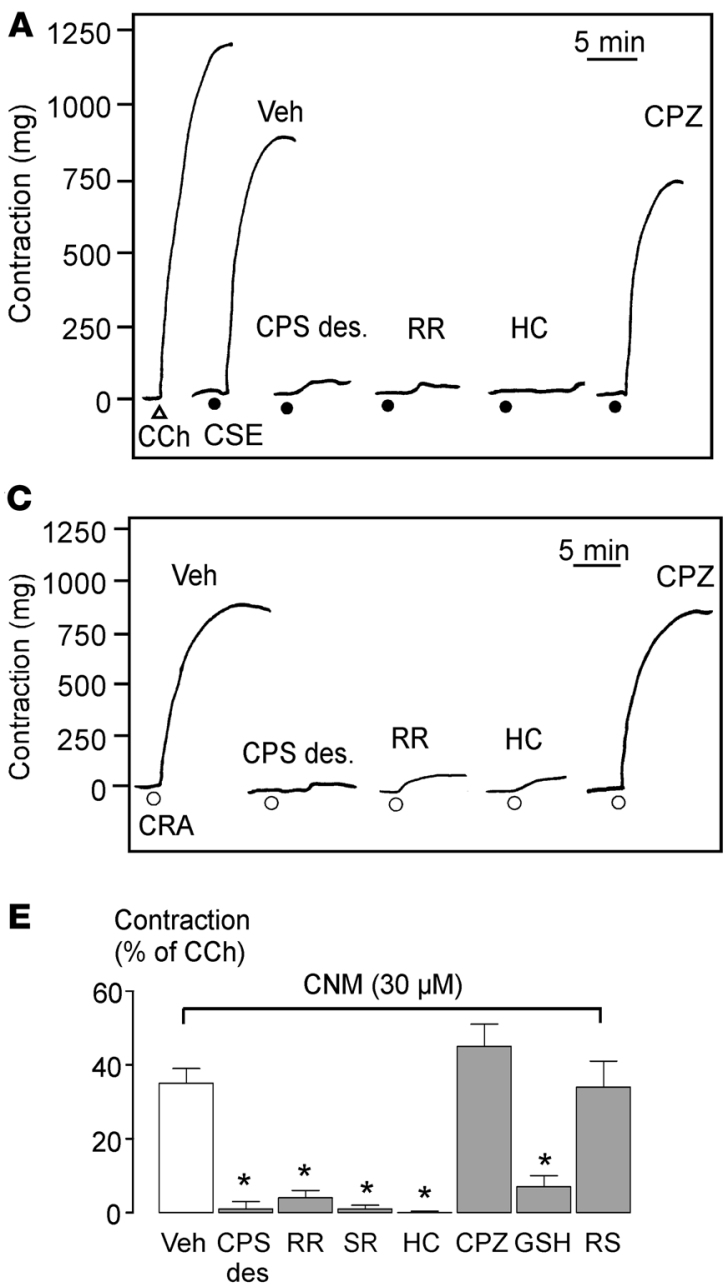
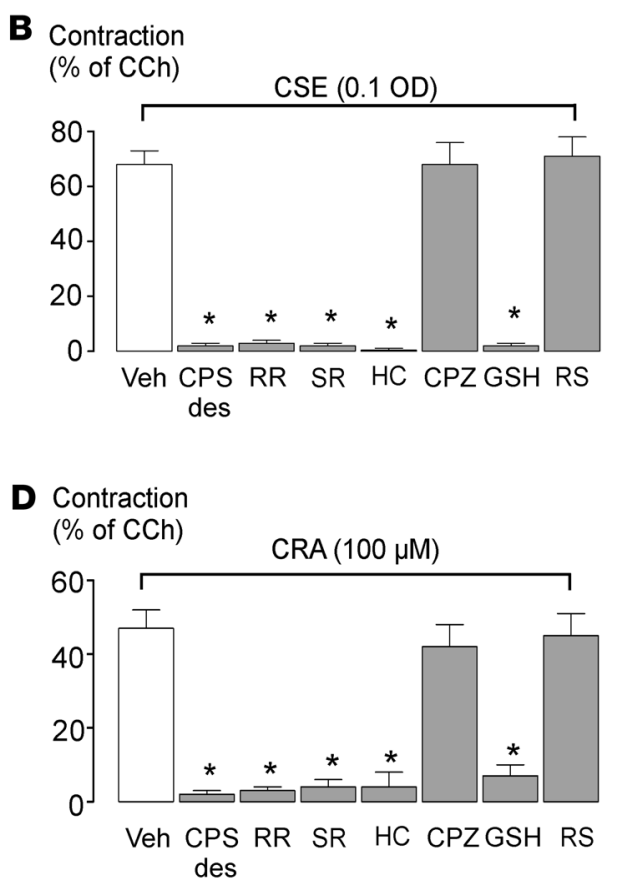

F Contraction
(\% of CCh)

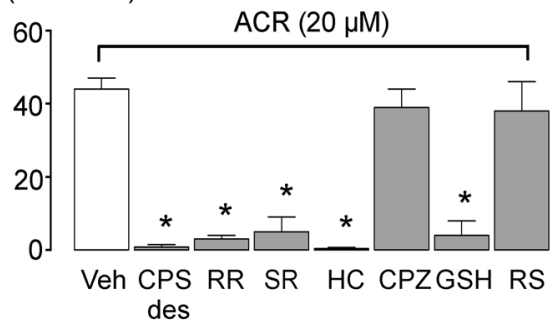

\section{Figure 4}

CSE and unsaturated aldehydes contract guinea pig isolated bronchus. (A and C) Typical traces and (B and D-F) pooled data of contractile responses to carbachol (CCh; $1 \mu \mathrm{M}$; triangle), CSE (0.1 OD; filled circles), crotonaldehyde $(100 \mu \mathrm{M}$; open circles), acrolein ( $20 \mu \mathrm{M})$, and cinnamaldehyde $(30 \mu \mathrm{M})$ in guinea pig isolated bronchus after capsaicin desensitization (20 $\mu \mathrm{M}$ for 20 minutes) or in the presence of $R R(30 \mu \mathrm{M})$, HC-030031 (50 $\mu \mathrm{M})$, capsazepine $(10 \mu \mathrm{M})$, SR 140333 plus SR 48968 (SR; both $1 \mu \mathrm{M})$, glutathione (10 $\mathrm{mM})$, or a combination of ROS scavengers (mannitol, $20 \mathrm{mM}$; ascorbic acid, $100 \mu \mathrm{M}$; lycopene, $10 \mu \mathrm{M}$; and $\beta$-carotene, $10 \mu \mathrm{M}$ ) or their respective vehicles. Each column represents the mean \pm SEM for at least 4 experiments. ${ }^{*} P<0.05$ versus Veh (1-way ANOVA, followed by Bonferroni's test). of CSE (1 OD; $25 \mu \mathrm{l})$ into the trachea of $\operatorname{Trpa1}^{+/+}$mice strongly stimulated extravasation of the Evans blue dye, a response that was completely absent in Trpa1-/- mice (Figure 5C). These results provide both pharmacological and genetic evidence that the TRPA1 ion channel is required to evoke airway inflammation by CS.

\section{Discussion}

Our study resulted in 2 important findings that we believe to be novel that are supported by pharmacological and genetic data. First, CS has the unique ability to excite capsaicin-sensitive primary sensory neurons by activating TRPA1 to induce neurogenic inflammation in the airways. Second, among approximately 5,000 constituents, acrolein and crotonaldehyde, which are the most abundant $\alpha, \beta$-unsaturated aldehydes in CS $(21,22)$, are the major mediators of CS-induced activation of TRPA1-expressing neurons. The 3 stimuli used in our experiments, CSE, acrolein, and crotonaldehyde, caused a robust and pharmacologically identical $\mathrm{Ca}^{2+}$ response in guinea pig JG neurons. The observations that the selective TRPV1 antagonist, capsazepine, was ineffective and that nonselective (camphor and RR) or selective (HC-030031) (24) TRPA1 antagonists blocked the $\mathrm{Ca}^{2+}$ response to CSE, crotonaldehyde, or acrolein, indicate that TRPA1 is the mediator of the neuronal excitation by the 3 stimuli. $\mathrm{Ca}^{2+}$ entry in nociceptors sensitive to capsaicin is associated with the release of the sensory neuropeptides SP, NKA, and CGRP. Our findings confirm previous reports that CS releases sensory neuropeptides (31) and show that in the guinea pig airways, a $\mathrm{Ca}^{2+}$-dependent neurosecretion from capsaicin-sensitive sensory nerve endings is evoked by the unsaturated aldehydes acrolein and crotonaldehyde.

The tachykinins SP and NKA mediate neurogenic inflammatory responses in the guinea pig airways, which consist mainly of bronchoconstriction (mediated by tachykinin NK1 and NK2 receptors) and plasma protein extravasation (mediated by NK1 receptors) (2). Inhaled CS reportedly produces an early phase of bronchoconstriction, mediated by both a cholinergic reflex and tachykinin release from sensory neurons, and a late phase caused by cyclooxygenase metabolites of arachidonic acid (32). The component of bronchoconstriction, mediated by SP/NKA release from sensory nerve terminals, seems to be the most prominent contributing mechanism (31). Our results show that the rapidly developing, indomethacin- and atropine-resistant in vitro bronchoconstrictions evoked by CSE, acrolein, and crotonaldehyde were abated by capsaicin desensitization and by a combination of tachykinin NK1 and NK2 receptor antagonists. Capsaicin has the unique property to excite and desensitize sensory neurons by stimulating TRPV1, a nonselective cation channel that is also activated by noxious heat (3), low extracellular $\mathrm{pH}(33,34)$, and some lipid molecules $(35-37)$. Capsaicin desensitization, which results from prolonged contact 


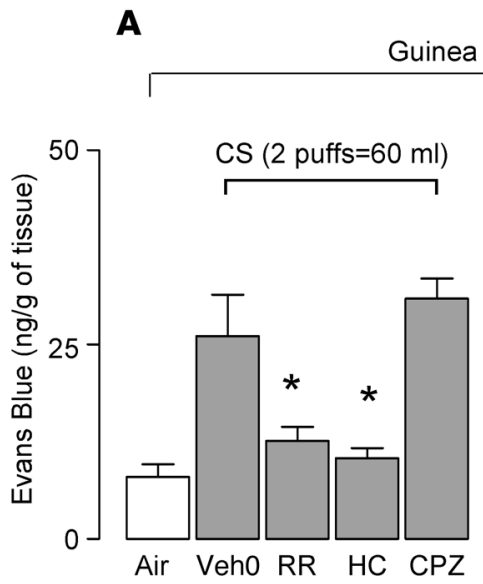

Figure 5

CS and CSE increase tracheal plasma extravasation. Effect of intratracheal RR (4.5 $\mathrm{nmol} / 150 \mu \mathrm{l}), \mathrm{HC}-030031(45 \mathrm{nmol} / 150 \mu \mathrm{l})$, capsazepine $(45 \mathrm{nmol} / 150 \mu \mathrm{l})$, or their respective vehicles $(150 \mu \mathrm{l})$ on the increase in plasma extravasation produced by $(\mathbf{A})$ CS inhalation $(2$ puffs $=60 \mathrm{ml})$ or $($ B $)$ capsaicin administration $(1 \mu \mathrm{mol} / \mathrm{kg}$, i.v. $)$ in anesthetized guinea pigs. Columns represent the mean \pm SEM of a least 4 experiments. Veh0, vehicles of RR, HC, and CPZ; Veh1, vehicle of CPS; Veh2, vehicles of $\mathrm{HC}$ and CPZ. ${ }^{*} P<0.05$ versus Veh; $\# P<0.05$ versus Veh2. C shows plasma extravasation evoked by intratracheal instillation of CSE vehicle (WT Veh; $25 \mu \mathrm{l}$ ) or CSE in wild-type or CSE in TRPA1-deficient mice. ${ }^{\S}<0.05$ versus WT (1-way ANOVA, followed by Bonferroni's test).

of isolated tissues with high capsaicin concentrations, is a widely used procedure that renders sensory nerve terminals unresponsive to capsaicin and to any other irritant stimulus $(4,38)$. Therefore, our findings indicate that bronchoconstriction evoked by CSE or unsaturated aldehydes is a neurogenic inflammatory response. The observation that responses to CSE and unsaturated aldehydes in isolated bronchi, like the $\mathrm{Ca}^{2+}$ response in cultured neurons, were insensitive to capsazepine but were completely abated by $\mathrm{HC}$ 030031 suggests a major role for TRPA 1 in these responses.

CS contains a large array of chemical species that potentially may stimulate sensory neurons and TRPA1. Nicotine has been recently shown to excite rat sensory neurons in a hexamethonium-sensitive manner (30). However, both hexamethonium and mecamylamine, 2 nicotinic receptor antagonists, at concentrations that blocked nicotine-evoked effects, failed to affect the $\mathrm{Ca}^{2+}$ response elicited by $\mathrm{CSE}$ in guinea pig JG neurons. Moreover, because the $\mathrm{Ca}^{2+}$ response to nicotine was insensitive to HC-030031, the contribution of nicotine to CS-evoked neurogenic inflammation can be considered absent or minor. Glutathione, a natural scavenger of unsaturated aldehydes (21), abated either CSE-evoked $\mathrm{Ca}^{2+}$ response in neurons or bronchoconstriction, thus corroborating the hypothesis that acrolein and crotonaldehyde mediate the effects of CSE. Nevertheless, it should be considered that glutathione can also scavenge ROS and that CS contains ROS (39). However, 4 diverse ROS scavengers (mannitol, ascorbic acid, lycopene, and $\beta$-carotene), which target different oxygen species, including superoxide, hydroxyl radical, peroxyl radicals, sulphur radicals, nitrogen-oxygen radicals, and singlet oxygen (40-43), failed to affect the $\mathrm{Ca}^{2+}$ response or the bronchoconstrictor effect of CSE. $\mathrm{H}_{2} \mathrm{O}_{2}$, which produces ROS, has been recently reported to stimulate TRPA1 (25). We confirmed these findings in guinea pig JG neurons. However, important differences were observed between responses evoked by $\mathrm{H}_{2} \mathrm{O}_{2}$ and CSE. As reported previously (25), the $\mathrm{Ca}^{2+}$ response to $\mathrm{H}_{2} \mathrm{O}_{2}$

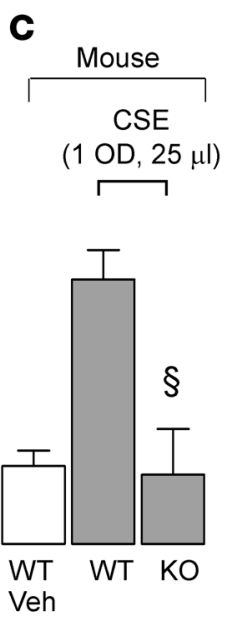

was delayed in onset, because it became visible after 20-40 seconds and reached a maximum effect within 60-200 seconds. In contrast, the response to CSE was immediate, reaching a maximum effect within 5-10 seconds. The response to $\mathrm{H}_{2} \mathrm{O}_{2}$ was inhibited by ROS scavengers, whereas that to CSE was not affected by this pharmacological intervention. Finally, the levels of $\mathrm{H}_{2} \mathrm{O}_{2}$ in CSE were reported to be in the low $\mu \mathrm{M}$ range (44). These low concentrations in our and previous (25) experiments failed to stimulate TRPA1.

Acetaldehyde, the most abundant saturated aldehyde contained in CSE $(21,26,27)$, has been recently reported to activate TRPA1 expressed in recombinant systems $(28,29)$. In mouse DRG neurons, acetaldehyde reportedly caused both TRPA1-dependent and -independent responses only at very high concentrations ( $\geq 1 \mathrm{mM})$ (28). Our present observation in guinea pig JG neurons confirms that acetaldehyde $(5 \mathrm{mM}$ concentration) can evoke a weak $\mathrm{Ca}^{2+}$ response. Because this response was insensitive to HC-030031, the hypothesis that acetaldehyde targets TRPA1 in guinea pig neurons is not supported by present results. One possible explanation for these conflicting findings is that in guinea pig neurons, the non-TRPA1-dependent response to acetaldehyde prevails. Regardless of the conflicting findings, the acetaldehyde concentration $(\sim 0.1 \mathrm{mM}$; ref. 21$)$ contained in the most concentrated (0.1 OD) CSE preparation used throughout our study was unable to produce any measurable response in guinea pig (present data) or mouse (28) neurons. Finally, unlike unsaturated aldehydes, acetaldehyde in CSE is resistant to the scavenging action of GSH (21), which did abate CSE-evoked responses. Overall, present evidence indicates that nicotine, ROS, or acetaldehyde do not play a major role in CSE-evoked neurogenic inflammation, although a minor contribution by these agents contained in the inhaled CS gas phase can not be excluded.

CS stimulates extravasation of plasma proteins from postcapillary venules by releasing SP, which activates NK1 receptors (1). We confirmed our previous findings that TRPV1 is not the neuronal target of CS in this in vivo assay (6), because capsazepine was ineffective. We also observed that the nonselective TRP channel antagonist, RR, greatly prevented CS-induced plasma protein extravasation. The ability of the TRPA1 blocker, HC-030031, to selectively prevent CS-evoked plasma extravasation, without affecting the response to capsaicin, adds strong circumstantial evidence to the proposal that TRPA1 mediates this response. We believe that conclusive proof of the unique role of TRPA 1 and $\alpha, \beta$-unsaturated aldehydes in CS-evoked neuronal excitation was obtained from genetically manipulated bioassays. First, transfection of the TRPA1 into HEK293 cells conferred to these cells the ability to respond to unsaturated aldehydes and CSE. Second, DRG neurons from TRPA1-deficient mice failed to respond to acrolein (18), crotonaldehyde, and CSE (present study). Finally, and more importantly, in contrast with what occurred in wild-type mice, CSE failed to produce any plasma protein extravasation in the trachea of TRPA1deficient mice. Thus, our genetic results demonstrate that TRPA1 is necessary and sufficient to mediate the sensory neuronal excitation by CS to produce neurogenic inflammation. 
Acrolein and crotonaldehyde recapitulated all the effects evoked by CSE in all the bioassays. However, the important question arises as to whether the effects produced by CSE are entirely mediated by the unsaturated aldehydes, acrolein, and crotonaldehyde contained therein. Concentrations of unsaturated aldehydes in CSE (0.1 OD) used in the present experiments (21) were approximately $15 \mu \mathrm{M}$. Concentration-response curves to acrolein and crotonaldehyde in neurons and in TRPA1-HEK293 cells indicated $\mathrm{EC}_{50}$ values ranging from 1 to $23 \mu \mathrm{M}$, thus making plausible the hypothesis that levels of unsaturated aldehydes in CSE are sufficient to activate TRPA1 and evoke neurogenic inflammation. Nevertheless, a minor contribution of components of CS, sensitive to the scavenging action of GSH and different from unsaturated aldehydes acting via TRPA1 receptor stimulation, can not be excluded completely.

The general hypothesis that protracted and uncontrolled neurogenic inflammation may contribute to various diseases, including asthma or COPD, is supported by a large body of evidence (2, $45)$. However, neurogenic inflammation in various tissues, including the airways, has also been proposed to be part of a protective mechanism, referred to as the nocifensor system (46-48). Thus, plasma protein extravasation and other neurogenic inflammatory responses evoked by TRPA1 stimulation by unsaturated aldehydes contained in CS may be an early protective response against the detrimental action of CS to the airways and lung tissue (49). Loss of sensitivity to the irritant effect of unsaturated aldehydes at the TRPA1 channel might reduce or abolish the protective action of the nocifensor system. Currently, the prevalent pathophysiological role of capsaicin-sensitive sensory nerves in chronic models of COPD is unknown. However, our present study that identifies the molecular mechanism by which CS stimulates airway sensory nerves is the first step toward a better understanding of the role of neurogenic inflammation in the pathophysiology of CS-evoked diseases.

\section{Methods}

Animals. Experiments were approved by Institutional Animal Care and Use Committees of the University of Florence or of the UCSF. Male DunkinHartley guinea pigs $(250 \mathrm{~g})$ were from AA Pampaloni. Mice deficient in TRPA1 were generated as described (18). Heterozygotes were mated to produce paired, wild-type (Trpa1 $\left.1^{+/}\right)$and knockout (Trpa1 $\left.1^{-/}\right)$littermates on a C57BL/ 6 background for all studies. Germline transmission of the mutated allele and excision of the selection cassette were verified by PCR analysis and Southern blotting. The gender of newborn pups was determined by PCR amplification of Y chromosome-specific (Sry) sequences. All animals were housed in a temperature- and humidity-controlled vivarium (12-hour dark/light cycle, with free access to food and water) for at least 5 days before the experiments.

TRPA1 HEK293 cells. cDNA encoding rat TRPA1 was a gift from David Julius (UCSF). An HA11 epitope was added to the C terminus of rat TRPA1 cDNA and introduced into the pcDNA5/FRT/TO expression vector. The construct was sequenced to verify integrity. HEK293 FLPTREX cells (Invitrogen) stably expressing rat TRPA1-HA11 or vector control (empty vector) (50) were created with the Flp-In system (Invitrogen) according to the manufacturer's guidelines, and cells were grown in DMEM supplemented with $10 \%$ HIFBS, $100 \mu \mathrm{g} / \mathrm{ml}$ hygromycin B, and $5 \mu \mathrm{g} / \mathrm{ml}$ blasticidin, in $95 \%$ air, $5 \% \mathrm{CO}_{2}$ at $37^{\circ} \mathrm{C}$. TRPA1 expression was induced by adding tetracycline $(0.1 \mu \mathrm{g} / \mathrm{ml})$ to medium 16 hours before experiments. Cells were plated onto coverslips coated with poly-D-lysine $(100 \mu \mathrm{g} / \mathrm{ml})$ as described previously (51). The same plating procedure was used for $\mathrm{Ca}^{2+}$ imaging experiments.

Mouse DRG neurons and guinea pigJG neurons. Mice were killed using sodium pentobarbital (200 mg/kg, i.p.). DRG from thoracic and lumbar spinal cord were minced in cold HBSS and prepared as previously described (52). Ganglia were digested by incubation in DMEM containing $1 \mathrm{mg} / \mathrm{ml}$ collagenase type $1 \mathrm{~A}$ and $0.8 \mathrm{mg} / \mathrm{ml}$ DNAse type IV for 60 minutes at $37^{\circ} \mathrm{C}$ and then incubated in DMEM containing $0.25 \%$ trypsin for 45 minutes at $37^{\circ} \mathrm{C}$. After digestion, soybean trypsin inhibitor (Sigma-Aldrich) was added to neutralize trypsin. Neurons were pelleted, suspended in DMEM containing $10 \%$ fetal bovine serum, $10 \%$ horse serum, $100 \mathrm{U} / \mathrm{ml}$ penicillin, $0.1 \mathrm{mg} / \mathrm{ml}$ streptomycin, and $2 \mathrm{mM}$ L-glutamine, dissociated by gentle trituration until the solution appeared cloudy and homogeneous, and plated on glass coverslips coated with Matrigel (BD Biosciences). Neurons were cultured for 3-4 days before the experiment. Guinea pig JG were removed, placed in cold HBSS, and transferred to collagenase $(2 \mathrm{mg} / \mathrm{ml})$, trypsin $(1 \mathrm{mg} / \mathrm{ml})$, and DNAse $(1 \mathrm{mg} / \mathrm{ml})$ for 35 minutes at $37^{\circ} \mathrm{C}$. Ganglia, placed in cold DMEM supplemented with $10 \%$ fetal bovine serum, $10 \%$ horse serum, $2 \mathrm{mM}$ L-glutamine, $100 \mathrm{U} / \mathrm{ml}$ penicillin, and $100 \mu \mathrm{g} / \mathrm{ml}$ streptomycin, were dissociated in single cells by several passages through a series of syringe needles. Medium and ganglia cells were filtered to remove debris, topped up with $8 \mathrm{ml}$ of DMEM medium, and centrifuged. The pellet was resuspended in DMEM medium and plated on poly-L-lysine $(8.3 \mu \mathrm{M})$ and laminin $(5 \mu \mathrm{M})$ coated $25 \mathrm{~mm}$ glass cover slips.

$\mathrm{Ca}^{2+}$ imaging. For $\mathrm{Ca}^{2+}$ fluorescence measurements, plated cells (HEK, guinea pig, or mouse neurons) were loaded with Fura-2, AM-ester $(5 \mu \mathrm{M}$; Invitrogen) in a buffer solution containing the following for 40 minutes at $37^{\circ} \mathrm{C}: \mathrm{CaCl}_{2}, 1.6 \mathrm{mM}$; KCl, $5.4 \mathrm{mM} ; \mathrm{MgSO}_{4}, 0.4 \mathrm{mM} ; \mathrm{NaCl}, 135 \mathrm{mM}$; D-glucose, $5 \mathrm{mM}$; HEPES, $10 \mathrm{mM}$; and BSA, 0.1\%, at pH 7.4. Cells were washed and transferred to a chamber on the stage of a Nikon Eclipse TE2000U microscope (HEK and guinea pig neurons) or Zeiss Axiovert microscope (mouse DRG neurons). Fura-2, AM-ester was excited at 340 $\mathrm{nM}$ and $380 \mathrm{nM}$ to indicate relative $\left[\mathrm{Ca}^{2+}\right]_{\mathrm{i}}$ changes by the $\mathrm{F}_{340} / \mathrm{F}_{380}$ ratio, and mouse DRG neurons were recorded with a dynamic image analysis system (Metafluor software; Molecular Devices), and HEK and guinea pig neurons were recorded with Laboratory Automation 2.0 (RCS), as previously described $(50,53)$. DRG preparations were challenged with $\mathrm{KCl}$ at the end of each experiment to identify neurons. Results are expressed as the $\mathrm{F}_{340} / \mathrm{F}_{380} \mathrm{~nm}$ emission ratio.

Neuropeptide release. Slices $(\sim 0.4 \mathrm{~mm})$ of guinea pig airways were placed in a 1-ml chamber and stabilized for 60 minutes in Krebs solution containing captopril $(1 \mu \mathrm{M})$, phosphoramidon $(1 \mu \mathrm{M})$, and $0.1 \% \mathrm{BSA}$, at $37^{\circ} \mathrm{C}$. Fractions were collected every 10 minutes into ethanoic acid $(2 \mathrm{~N})$ before (20 minutes), during (10 minutes), and after (10 minutes) administration of stimuli; freeze-dried and reconstituted in assay buffer; and analyzed for CGRP and SP immunoreactivities by enzyme immunoassays as described previously (54). Crotonaldehyde, cinnamaldehyde (both $200 \mu \mathrm{M}$ ), or CSE (1.0 OD) did not show any crossreactivity with SP or CGRP antisera. Exposure to capsaicin $(10 \mu \mathrm{M})$ for 20 minutes provoked a specific and complete desensitization of TRPV1-expressing sensory nerve terminals, which became unresponsive to capsaicin itself and any other stimulus. Some experiments were repeated in $\mathrm{Ca}^{2+}$-free medium containing $1 \mathrm{mM}$ EDTA.

Organ bath studies. Main bronchi ( $\sim 2 \mathrm{~mm}$ each) were excised from guinea pigs and suspended at a resting tension of $1.5 \mathrm{~g}$ in 5 - $\mathrm{ml}$ organ baths. The tissues were bathed in an aerated $\left(95 \% \mathrm{O}_{2}\right.$ and $\left.5 \% \mathrm{CO}_{2}\right)$ Krebs-Henseleit solution, maintained at $37^{\circ} \mathrm{C}$, and contained the neutral endopeptidase inhibitor phosphoramidon $(1 \mu \mathrm{M})$, to minimize peptide degradation, and the cyclooxygenase inhibitor indomethacin $(5 \mu \mathrm{M})$, to prevent prostanoids generation. Tissues were equilibrated for 60 minutes before the experiment began, and then contracted with carbachol $(1 \mu \mathrm{M})$, to record the maximal contractile response of each preparation as reported (55). After carbachol washout, atropine $(1 \mu \mathrm{M})$ was added to the buffer solution and left in contact with preparations for the entire duration of the experiment. The contractile responses to CSE, crotonaldehyde, acrolein, and cinnamalde- 
hyde were obtained either in the presence of various receptor antagonists and ROS or aldehyde scavengers (15 minutes incubation each) or of their respective vehicles. In another set of experiments, airway preparations were preincubated for 20 minutes with a capsaicin concentration $(20 \mu \mathrm{M})$ known to render capsaicin-sensitive sensory nerve endings unresponsive to capsaicin itself and to any other stimulus $(4,38)$. The bathing fluid was then changed repeatedly (every 5 minutes over a period of 30 minutes) until the contractile response to capsaicin had returned to baseline. At this point, preparations were challenged with CSE, crotonaldehyde, acrolein, or cinnamaldehyde, and the responses elicited by these agonists were compared with those obtained in preparations pretreated with capsaicin vehicle. Motor activity of bronchial preparations was recorded isometrically on a force transducer (Ugo Basile).

Plasma protein extravasation. Anesthetized (sodium pentobarbital, $60 \mathrm{mg} /$ $\mathrm{kg}$, i.p.) guinea pigs were artificially ventilated ( 60 breaths $/ \mathrm{min}$ with a tidal volume of $6 \mathrm{ml}$ ). After a 30-minute stabilization period, animals received Evans Blue dye (30 mg/kg, i.v.), and, 1 minute later, were treated with intravenous capsaicin or its vehicle or they inhaled CS or room air (control, both $60 \mathrm{ml}=2$ puffs) through a tracheal cannula. Antagonists (capsazepine, RR, or HC-030031, intratracheally) or their respective vehicles were administered 15 minutes before the stimulus. Preliminary experiments (data not shown) indicated that capsazepine, RR, or HC-030031 did not affect baseline Evans blue dye extravasation. In a further series of experiments, anesthetized (xylazine, $100 \mathrm{mg} / \mathrm{kg}$, i.m. and ketamine, $50 \mathrm{mg} / \mathrm{kg}$, i.m.) Trpa1 $1^{-/}$or $\operatorname{Trpa1} 1^{+/+}$mice were treated with CSE (1.0 OD; $25 \mu \mathrm{l}$ ) by intratracheal instillation 1 minute after Evans blue dye injection $(30 \mathrm{mg} /$ $\mathrm{kg}$, i.v.). Fifteen minutes after administration of the different stimuli, animals were transcardially perfused with $0.9 \%$ saline to remove the Evans blue dye from the circulation. Tracheas were removed and after extraction by overnight incubation in formamide, the extravasated dye was measured by spectrophotometry at $620 \mathrm{~nm}$, as reported (54).

Reagents. CSE was generated as reported previously (21) from the combustion of 4-6 cigarettes (Marlboro Red; $12 \mathrm{mg}$ tar, $0.9 \mathrm{mg}$ nicotine each) bubbled through $50 \mathrm{ml}$ of buffer. Absorbance (OD) was measured at 320 $\mathrm{nm}$. SR 140333 and SR 48968 were gifts of X. Emonds-Alt (Sanofi-Aventis). Fura-2, AM was from Alexis Biochemicals or Molecular Probes. HC-030031 or 2-(1,3-dimethyl-2,6-dioxo-1,2,3,6-tetrahydro-purin-7-yl)-N-(4-isopropylphenyl)-acetamide was synthesized at the Department of Pharmaceutical Chemistry, University of Ferrara, by reacting theophyllin-7-acetic acid with an equimolar amount of 4-isopropylaniline in the presence of EDC (1-ethyl-3-[3-dimethylaminopropyl]carbodiimide hydrochloride) and HOBt (N-hydroxybenzotriazole). The structure of the compound was assigned by H-NMR and mass spectroscopy. All other chemicals were obtained from Sigma-Aldrich. Capsaicin was dissolved in ethanol, and camphor, capsazepine, lycopene, $\beta$-carotene, SR 48968, and SR 140333 were dissolved in DMSO at a $10-\mathrm{mM}$ concentration, and further dilutions were made in isotonic saline. All the other reagents were dissolved in isotonic saline.

Statistics. All data are presented as mean \pm SEM or CI. Data were compared using ANOVA and Bonferroni's test. Agonist potency was expressed as $\mathrm{EC}_{50}$, that is, the molar concentration of agonist producing $50 \%$ of the measured effect. $P$ values of less than 0.05 were considered significant.

\section{Acknowledgments}

Supported by grants from MiUR, Rome (FIRB, RBIP06YM29 to P. Geppetti and R. Patacchini), PRIN (2003054380), Ente Cassa di Risparmio di Firenze (to P. Geppetti), and NIH (DK39957, DK43207, DK57840 to N.W. Bunnett) We are grateful to David Julius (UCSF Departments of Physiology and Cellular and Molecular Pharmacology) for the generous gift of TRPA1-deficient mice, Fabrizio Facchinetti (Chiesi Pharmaceuticals, Parma, Italy) for useful suggestions on CSE preparation, and Pamela Derish (Publications Manager, UCSF Department of Surgery) for the revision of the English text.

Received for publication December 27, 2007, and accepted in revised form April 23, 2008.

Address correspondence to: Pierangelo Geppetti, Department of Preclinical and Clinical Pharmacology, Viale Pieraccini 6, I-50139 Florence, Italy. Phone: 39-055-427-1329; Fax: 39-055-427-1280; E-mail: pierangelo.geppetti@unifi.it.

Serena Materazzi and Pierangelo Geppetti's present address is: Department of Preclinical and Clinical Pharmacology, University of Florence, Florence, Italy.

Eunice Andrè and Barbara Campi contributed equally to this work.
1. Lundberg, J.M., and Saria, A. 1983. Capsaicininduced desensitization of airway mucosa to cigarette smoke, mechanical and chemical irritants. Nature. 302:251-253.

2. Geppetti, P., and Holzer, P. 1996. Neurogenic inflammation. CRC Press. Boca Raton, Florida, USA. 256 pp.

3. Caterina, M.J., et al. 1997. The capsaicin receptor: a heat-activated ion channel in the pain pathway. Nature. 389:816-824.

4. Szallasi, A., and Blumberg, P.M. 1999. Vanilloid (capsaicin) receptors and mechanisms. Pharmacol. Rev. 51:159-212.

5. Bevan, S., et al. 1992. Capsazepine: a competitive antagonist of the sensory neurone excitant capsaicin. Br. J. Pharmacol. 107:544-552.

6. Geppetti, P., et al. 1993. Ruthenium red, but not capsazepine reduces plasma extravasation by cigarette smoke in rat airways. Br. J. Pharmacol. 108:646-650.

7. Amann, R., and Maggi, C.A. 1991. Ruthenium red as a capsaicin antagonist. Life Sci. 49:849-856.

8. Alessandri-Haber, N., et al. 2003. Hypotonicity induces TRPV4-mediated nociception in rat. Neuron. 39:497-511.

9. Bautista, D.M., et al. 2007. The menthol receptor TRPM8 is the principal detector of environmental cold. Nature. 448:204-208.

10. Caterina, M.J., Rosen, T.A., Tominaga, M., Brake, A.J., and Julius, D. 1999. A capsaicin-receptor homologue with a high threshold for noxious heat. Nature. 398:436-441.

11. Liedtke, W., et al. 2000. Vanilloid receptor-related osmotically activated channel (VR-OAC), a candidate vertebrate osmoreceptor. Cell. 103:525-535.

12. McKemy, D.D., Neuhausser, W.M., and Julius, D. 2002. Identification of a cold receptor reveals a general role for TRP channels in thermosensation. Nature. 416:52-58.

13. Peier, A.M., et al. 2002. A TRP channel that senses cold stimuli and menthol. Cell. 108:705-715.

14. Nagata, K., Duggan, A., Kumar, G., and GarciaAnoveros, J. 2005. Nociceptor and hair cell transducer properties of TRPA1, a channel for pain and hearing. J. Neurosci. 25:4052-4061.

15. Story, G.M., et al. 2003. ANKTM1, a TRP-like channel expressed in nociceptive neurons, is activated by cold temperatures. Cell. 112:819-829.

16. Nassenstein, C., et al. 2008. Expression and function of the ion channel TRPA1 in vagal afferent nerves innervating mouse lungs. J. Physiol. 586:1595-1604.

17. Bandell, M., et al. 2004. Noxious cold ion channel
TRPA1 is activated by pungent compounds and bradykinin. Neuron. 41:849-857.

18. Bautista, D.M., et al. 2006. TRPA1 mediates the inflammatory actions of environmental irritants and proalgesic agents. Cell. 124:1269-1282.

19. Jordt, S.E., et al. 2004. Mustard oils and cannabinoids excite sensory nerve fibres through the TRP channel ANKTM1. Nature. 427:260-265.

20. Macpherson, L.J., et al. 2005. The pungency of garlic: activation of TRPA1 and TRPV1 in response to allicin. Curr. Biol. 15:929-934.

21. Facchinetti, F., et al. 2007. Alpha,beta-unsaturated aldehydes in cigarette smoke release inflammatory mediators from human macrophages. Am. J. Respir. Cell Mol. Biol. 37:617-623.

22. Huber, G.L., First, M.W., and Grubner, O. 1991. Marijuana and tobacco smoke gas-phase cytotoxins. Pharmacol. Biochem. Behav. 40:629-636.

23. Xu, H., Blair, N.T., and Clapham, D.E. 2005. Camphor activates and strongly desensitizes the transient receptor potential vanilloid subtype 1 channel in a vanilloid-independent mechanism. J. Neurosci. 25:8924-8937.

24. McNamara, C.R., et al. 2007. TRPA1 mediates formalin-induced pain. Proc. Natl. Acad. Sci. U. S. A. 104:13525-13530. 
25. Andersson, D.A., Gentry, C., Moss, S., and Bevan, S. 2008. Transient receptor potential A1 is a sensory receptor for multiple products of oxidative stress. J. Neurosci. 28:2485-2494.

26. Fujioka, K., and Shibamoto, T. 2006. Determination of toxic carbonyl compounds in cigarette smoke. Environ. Toxicol. 21:47-54.

27. Witschi, H. 2005. Carcinogenic activity of cigarette smoke gas phase and its modulation by beta-carotene and N-acetylcysteine. Toxicol. Sci. 84:81-87.

28. Bang, S., Kim, K.Y., Yoo, S., Kim, Y.G., and Hwang, S.W. 2007. Transient receptor potential A1 mediates acetaldehyde-evoked pain sensation. Eur. J. Neurosci. 26:2516-2523.

29. Macpherson, L.J., et al. 2007. An ion channel essential for sensing chemical damage. J. Neurosci. 27:11412-11415.

30. Xu, J., Yang, W., Zhang, G., Gu, Q., and Lee, L.Y. 2007. Calcium transient evoked by nicotine in isolated rat vagal pulmonary sensory neurons. Am.J. Physiol. Lung. Cell. Mol. Physiol. 292:L54-L61.

31. Lee, L.Y., Lou, Y.P., Hong, J.L., and Lundberg, J.M. 1995. Cigarette smoke-induced bronchoconstriction and release of tachykinins in guinea pig lungs. Respir. Physiol. 99:173-181.

32. Hong, J.L., Rodger, I.W., and Lee, L.Y. 1995. Cigarette smoke-induced bronchoconstriction: cholinergic mechanisms, tachykinins, and cyclooxygenase products. J. Appl. Physiol. 78:2260-2266.

33. Bevan, S., and Geppetti, P. 1994. Protons: small stimulants of capsaicin-sensitive sensory nerves. Trends Neurosci. 17:509-512.

34. Tominaga, M., et al. 1998. The cloned capsaicin receptor integrates multiple pain-producing stimuli. Neuron. 21:531-543.

35. Huang, S.M., et al. 2002. An endogenous capsaicinlike substance with high potency at recombinant and native vanilloid VR1 receptors. Proc. Natl. Acad. Sci.U.S. A. 99:8400-8405.

36. Zygmunt, P.M., et al. 1999. Vanilloid receptors on sensory nerves mediate the vasodilator action of anandamide. Nature. 400:452-457.

37. Hwang, S.W., et al. 2000. Direct activation of capsaicin receptors by products of lipoxygenases: endogenous capsaicin-like substances. Proc. Natl. Acad. Sci. U. S. A. 97:6155-6160.

38. Szolcsanyi, J. 1977. A pharmacological approach to elucidation of the role of different nerve fibres and receptor endings in mediation of pain. J. Physiol. (Paris). 73:251-259.

39. Church, D.F., and Pryor, W.A. 1985. Free-radical chemistry of cigarette smoke and its toxicological implications. Environ. Health Perspect. 64:111-126.

40. Ambrosio, G., and Flaherty, J.T. 1992. Effects of the superoxide radical scavenger superoxide dismutase, and of the hydroxyl radical scavenger mannitol, on reperfusion injury in isolated rabbit hearts. Cardiovasc. Drugs Ther. 6:623-632.

41. Di Mascio, P., Kaiser, S., and Sies, H. 1989. Lycopene as the most efficient biological carotenoid singlet oxygen quencher. Arch. Biochem. Biophys. 274:532-538.

42. Padayatty, S.J., et al. 2003. Vitamin C as an antioxidant: evaluation of its role in disease prevention. J. Am. Coll. Nutr. 22:18-35.

43. Tapiero, H., Townsend, D.M., and Tew, K.D. 2004 The role of carotenoids in the prevention of human pathologies. Biomed. Pharmacother. 58:100-110.

44. Yan, F., et al. 2005. Near-real-time determination of hydrogen peroxide generated from cigarette smoke. J. Environ. Monit. 7:681-687.

45. Joos, G.F., and Pauwels, R.A. 2001. Tachykinin receptor antagonists: potential in airways diseases. Curr. Opin. Pharmacol. 1:235-241.
46. Holzer, P., et al. 1990. Afferent nerve-mediated protection against deep mucosal damage in the rat stomach. Gastroenterology. 98:838-848.

47. Jimba, M., et al. 1995. Role of C fibers in physiological responses to ozone in rats. J. Appl. Physiol. 78:1757-1763.

48. Lewis, T. 1936. Experiments relating to cutaneous hyperalgesia and its spread through somatic nerves. Clin. Sci. 2:373-421.

49. Turner, C.R., Stow, R.B., Talerico, S.D., Christian, E.P., and Williams, J.C. 1993. Protective role for neuropeptides in acute pulmonary response to acrolein in guinea pigs. J. Appl. Physiol. 75:2456-2465.

50. Cottrell, G.S., et al. 2007. Post-endocytic sorting of calcitonin receptor-like receptor and receptor activity-modifying protein $1 . \mathrm{J}$. Biol. Chem. 282:12260-12271.

51. Trevisani, M., et al. 2007. 4-Hydroxynonenal, an endogenous aldehyde, causes pain and neurogenic inflammation through activation of the irritant receptor TRPA1. Proc. Natl. Acad. Sci. U. S. A. 104:13519-13524.

52. Kayssi, A., Amadesi, S., Bautista, F., Bunnett, N.W. and Vanner, S. 2007. Mechanisms of proteaseactivated receptor 2-evoked hyperexcitability of nociceptive neurons innervating the mouse colon. J. Physiol. 580:977-991.

53. Tognetto, M., et al. 2001. Anandamide excites central terminals of dorsal root ganglion neurons via vanilloid receptor-1 activation. J. Neurosci. 21:1104-1109.

54. Trevisani, M., et al. 2002. Ethanol elicits and potentiates nociceptor responses via the vanilloid receptor-1. Nat. Neurosci. 5:546-551.

55. Trevisani, M., et al. 2004. Ethanol causes inflammation in the airways by a neurogenic and TRPV1dependent mechanism. J. Pharmacol. Exp. Ther. 309:1167-1173. 